\title{
A PEDAGOGIA FREIRIANA SOB A PERSPECTIVA DA EDUCAÇÃO POPULAR EM TEMPOS DE NEGACIONISMO
}

\section{FREIRIANA PEDAGOGY UNDER THE PERSPECTIVE OF POPULAR EDUCATION IN TIMES OF NEGATIONISM}

\author{
Valdirene Eliane Bailon de Souza \\ Nádia Marota Minó \\ Rita Márcia Andrade Vaz de Mello
}

\section{RESUMO}

Neste artigo, visamos refletir sobre a Pedagogia Freiriana, no que diz respeito à abordagem da Educação Popular em espaços distintos, sobretudo em tempos de negacionismo. A Educação Popular, tão enfatizada na literatura de Freire, sempre esteve pautada no caráter social e político, em defesa da parte excluída e oprimida da sociedade. Assim, para a realização do presente estudo, fizemos, inicialmente, um levantamento bibliográfico das obras de Paulo Freire, a fim de evidenciar a importância de seu legado, que sempre foi baseado no princípio da coletividade, ao demonstrar preocupação com todos(as). Percebemos que tal premissa está em inconsonância com o atual sistema no poder, que por sua vez é movido por interesses próprios, desdenhando os pensamentos de esquerda e ditos como comunistas. Desse modo, com a intenção de oferecer autonomia e capacidade crítica aos sujeitos, recomendamos uma compreensão ético-política para assumirmos nossa responsabilidade para/com o "outro", diante da necessidade de pensarmos o nosso tempo, planejarmos o futuro e construirmos o inédito viável, conforme defendido por Freire.

Palavras-chave: Pedagogia freiriana; Educação popular; Negacionismo.

\begin{abstract}
In this article, we aim to reflect on Freiriana Pedagogy, with regard to the approach of Popular Education in different spaces, especially in times of denial. Popular Education, so emphasized in Freire literature, was always based on the social and political character, in defense of the excluded and oppressed part of society. Thus, to carry out this study, we initially carried out a bibliographical survey of Paulo Freire works, in order to highlight the importance of his legacy, which has always been based on the principle of collectivity, by showing concern for everyone. We realize that such a premise is inconsistent with the current system in power, which in turn is driven by its own interests, disdaining leftist thoughts and said to be communist. Thus, with the intention of offering autonomy and critical capacity to the subjects, we recommend an ethicalpolitical understanding to assume our responsibility to/with the "other", given the need to think about our time, plan the future and build the viable unprecedented, as defended by Freire.
\end{abstract}

Keywords: Freiriana pedagogy; Popular education; Negationism. 


\section{INTRODUÇÃO}

Como assunto central abordado no presente estudo, fundamentamos na Pedagogia Freiriana enquanto cerne para a Educação Popular de qualidade, em distintos espaços, proposição que deve ser reforçada mediante tempos de negacionismo ${ }^{1}$.

Apresentamos o negacionismo como a negação de fatos históricos e de tudo que se alcançou pelas ciências, sendo alimentado por informações falsas com a intenção de se instaurar a dúvida em determinados fatos e situações. São propagadas suspeitas em métodos e conhecimentos verídicos, apresentando como alternativa o saber construído a partir da experiência e de depoimentos (MOREL, 2021; VILELA; SELLES, 2020; ROQUE, 2020). Nesse sentido, percebemos o negacionismo de forma desatinada pelo governo contra a figura do educador Paulo Freire, que vai desde a negação da sua importância para a educação até a sua culpabilização pelos problemas da educação brasileira.

Sobre essa questão vale mencionar que embora o negacionismo científico e as pós-verdades guardem pontos em comum, existem contendas que valem a pena apontar. A primeira seria o negacionismo científico mantido por uma mentalidade arranjada, na qual há supostamente um grupo ou um conjunto de ideias, que representa o oposto dos valores que os grupos ultraconservadores desejam preservar, estando neles comunistas, esquerdistas, feministas, baderneiros, ateus, homossexuais, intelectuais, dentre outros, contra os guardiães da moralidade, que buscam resguardar os ditos "bons costumes" a todo custo. Por outro lado está o negacionismo científico elaborado pela comunidade científica, ou seja, a pós-verdade ${ }^{2}$ com caráter mais genérico e amplo.

\footnotetext{
${ }^{1} \mathrm{O}$ negacionismo é diverso e heterogêneo, formando um fenômeno complexo da negação de fatos estabelecidos, partindo de métodos escusos como a falsificação, o ataque e o descrédito na realidade cientificamente comprovada. De acordo com Morel (2021), o termo negacionismo, tal como o entendemos hoje, começou a ser utilizado pelo historiador francês Henry Rousso (1990) ao se referir àqueles que negavam o holocausto promovido pela Alemanha nazista na Segunda Guerra Mundial. Era preciso distinguir o trabalho corriqueiro do historiador - o questionamento permanente das interpretações históricas - da negação de fatos estabelecidos, partindo de métodos escusos como a falsificação, o ataque, o descrédito do testemunho de sobreviventes etc.

${ }^{2}$ Informação que distorce deliberadamente a verdade, ou algo real, caracterizada pelo forte apelo à emoção, e que, tomando como base crenças difundidas, em detrimento de fatos apurados, tende a ser aceita como verdadeira, influenciando a opinião pública e comportamentos sociais. Disponível em: <https://www.academia.org.br/nossa-lingua/nova-palavra/pos-verdade $>$. Acesso em: 31 out. 201.
} 
Informações são fabricadas ou distorcidas e acabam reforçando o preconceito e a intolerância sobre aqueles grupos que ameaçam os valores conservadores (VILELA; SELLES, 2020, p. 9).

Diante o cenário expresso a educação defendida por Paulo Freire é uma ferramenta de transformação social e um ato politico de resistência, frente a um momento marcado pela irracionalidade, pelo ódio e desprezo ao povo, de forma que o legado freiriano nunca se fez tão importante para a preservação da democracia e do estado de direito na sociedade brasileira (ROMÃO; ROMÃO, 2020).

Segundo Pini (2019), Paulo Freire iniciou a práxis da Educação Popular na década de 1960, no Brasil, ao perceber que o aumento do analfabetismo se destacava acima dos indicadores nacionais. Como homem apaixonado por sua terra e pelas pessoas, Freire tornou-se responsável por desenvolver pressupostos teóricos e metodológicos que pudessem intervir na realidade social de homens e mulheres. Nesse sentido, a Educação Popular enfatizada na literatura de Freire foi baseada no caráter político, a serviço de uma sociedade excluída e oprimida. De acordo com a Pedagogia Freiriana, a educação consiste no principal instrumento das classes populares para emancipação e libertação do sujeito. Em outros termos, a promoção do processo educativo, a partir da ótica da Educação Popular, configura um compromisso fidedigno e rigoroso com o próprio meio de existência, em luta por melhores condições sociais e culturais.

Importante ressaltarmos que várias práticas da Educação Popular assumem função significativa, não estando restritas a apenas um movimento de construção ideológica - trata-se da orientação das relações sociais e de trabalho, além de ações políticas na realidade concreta, principalmente para reivindicar políticas públicas e melhorias em geral para a realidade do povo. Com base nas informações elencadas, a educação popular não se restringe apenas a adultos, ou seja, ocorre nas escolas públicas e comunitárias assim como ONGs de todo o Brasil, com o objetivo de contribuir para uma sociedade mais justa e democrática, mas, principalmente para que as classes discriminadas tomem consciência das suas condições e os problemas que as atingem. 
O ano de 2021 marca a comemoração do centenário de Paulo Freires, sendo relevante discutir sua vida e obra, sobretudo quanto às premissas da Educação Popular, já que esse autor assumiu a condição de patriota injustiçado, ao arriscar a própria liberdade para abrir as portas do mundo, da história e da cultura aos analfabetos, oprimidos e excluídos. Sua escolha humanitária custou um exílio que durou 16 anos, mas lhe trouxe o acesso ao mundo e a todos(as) ao mundo dele. Diante da trajetória de dúvidas, medos, incertezas e apontamentos dos contrários à sua proposta de vida, Freire conquistou espaço por sua "ousadia, com valentia e tenacidade, acreditando nas pessoas, nos sonhos democráticos, num Brasil em um mundo próspero com a participação das camadas populares" (FREIRE, 2006, p. 128).

Consideramos que a Pedagogia Freiriana na realidade atual pode favorecer a articulação de uma educação que engloba ciência, arte e cultura, em tempos de negacionismo e de crise sanitária (Covid-19). Observamos, recorrentemente, discursos de ódio, fake news e ataques às instituições científicas, à educação e à saúde, o que reforça a necessidade de expor, a cada dia mais, o olhar Freiriano, que é um olhar de amor, de respeito, de acolhida e novas possibilidades, tanto na escola como nos espaços de educação não formal.

Para a realização do presente estudo, efetuamos, inicialmente, um levantamento bibliográfico das obras de Paulo Freire, buscando artigos e textos científicos que apresentem, de forma reflexiva, discussões envolvendo pressupostos da sua pedagogia.

Dessa forma, estruturamos o artigo em dois eixos, para além da parte introdutória e das considerações finais: primeiramente, realizamos uma contextualização das contribuições de Paulo Freire e de seu legado educacional, sobretudo no que tange a Educação Popular, uma vez que sua vida e obras e concretizou na práxis, enquanto militante, mas acima de tudo de um cidadão, junto aos movimentos sociais e demais espaços formativos. Ainda, no segundo eixo, pontuamos as dificuldades do meio educacional e científico frente a desvalorização e cortes recorrentes por parte do governo atual, explicitando os tempos obscuros que vivenciamos.

\footnotetext{
3 Paulo Reglus Neves Freire nasceu na Estrada do Encanamento, 724, no bairro de Casa Amarela, no Recife (PE), às $9 \mathrm{~h}$ da manhã, do dia 19 de setembro de 1921. Morreu na UTI do Hospital Albert Einstein, na cidade de São Paulo, às 6h30, do dia 2 de maio de 1997, de infarte agudo do miocárdio (FREIRE, 2006).
} 


\section{0 anos de Educação Popular com Paulo Freire: reflexões e novas teorizações}

Em seu período de vida, Paulo Freire foi pedagogo, escritor, filósofo, professor e, acima de tudo, humano. Iniciou seus trabalhos na educação de jovens e adultos, incluindo trabalhadores rurais, operários e pescadores ribeirinhos, no Rio Grande do Norte, onde em apenas 45 dias alfabetizou cerca de 300 educandos. Após essa primeira iniciativa, Freire desenvolveu um método inovador de alfabetização, que foi adotado primeiramente em Pernambuco, mas que depois ficou conhecido em território nacional e internacional (FREIRE, 2001).

Para recordar brevemente o contexto histórico, no início da década de 1980, período de transição política, o Brasil viveu um processo de redemocratização, surgindo a Educação Popular como concepção pedagógica. Na mesma época, Paulo Freire havia retornado ao país, após um exílio de 16 anos, assumindo a frente da Secretaria de Educação do Município de São Paulo, no governo da ex-prefeita Luiza Erundina de Sousa. Como secretário da pasta educacional, Freire construiu o Movimento de Alfabetização de Jovens e Adultos (Mova)4, e organizou um processo de redemocratização da escola pública, com base no argumento de que "mudar é difícil, mas é possível e urgente" (FREIRE, 2000, p.8).

Para complementação dessa proposição, citamos o livro intitulado "Alfabetização: leitura do mundo, leitura da palavra", que representa uma das importantes contribuições da Educação Popular, visto que retrata a educação de jovens e adultos (incluindo camponeses, operários e pescadores), precisamente em 1963. Voltado para classe popular, o educador adquiriu reconhecimento internacional, recebendo diversos convites para a coordenação de projetos de

${ }^{4}$ No Brasil, o Mova ainda é desenvolvido em diversas administrações populares com muitas variações, mas a proposta idealizada por Paulo Freire tem estado presente em ideias de participação popular, espírito democrático, combate ao autoritarismo e defesa de direitos (MENEZES, 2021). Disponível em: <https://www.educabrasil.com.br/mova/>. 
alfabetização em países africanos, conforme experiências relatadas no livro supracitado (FREIRE; MACEDO, 2013).

Para Freire, não bastava que as autoridades brasileiras buscassem somente o progresso econômico e social do país; ele defendia a política de Educação como base, sendo que, além da alfabetização, era necessária a adaptação dos desfavorecidos ao mundo moderno. Esse olhar especial, que abrangia os indivíduos do meio rural, para que eles tivessem acesso à leitura, à escrita, à convivência social e até mesmo às condições de higiene, o colocou em posição de cidadão participativo e crítico. Gohn (2002) descreve bem essa transição, ao apontar que o surgimento da Educação Popular era pautado em ideais Freirianos, estando centrado nos sujeitos, em sua cultura e em suas representações.

Sobre a denominação do que realmente representa a Educação Popular, Freire explicita, em seu livro Ação cultural para a liberdade, de 2007, que a

Educação Popular é a que, substantivamente democrática, jamais separa do ensino dos conteúdos o desvelamento da realidade. É a que estimula a presença organizada das classes sociais populares na luta em favor da transformação democrática da sociedade, no sentido da superação das injustiças (FREIRE, 2007, p. 103-105).

Para Freire, qualquer que seja o espaço formador, o educador/mediador necessita ter ampla responsabilidade no intuito de que os educandos consigam compreender a dimensão mais profunda do processo de aprendizagem. Assim, a intervenção deve ocorrer como ato consciente do processo de ensinoaprendizagem, momento em que o docente intervém para que eles percebam a dimensão das coerções sociais que estabelecem as assimetrias entre os sujeitos que detêm ou não o poder (FREIRE, 2007).

Além disso, sua obra retrata justamente as diferenças que são impostas no meio social, por meio da educação. Freire (2009, p. 23) postula que "o ato de estudar demanda humildade”. Assim, se o sujeito que estuda assume uma posição humilde, coerente com a atitude crítica, ele não se sente diminuído caso encontre dificuldades, reforçando a significação mais profunda do espaço habitado.

Desse modo, é preciso reacender os princípios Freirianos, diante da situação de negacionismo da educação e da ciência, sobretudo no ano do seu 
centenário. Sua grandiosa obra teórica possui incontestável "gentidade posta ao lado de sua epistemologia a serviço de homens e de mulheres de todo o mundo"(FREIRE, 2006, p. 18).

Salientamos que a teoria Freiriana é pautada em elementos aglutinadores das massas, estratégia de eliminação do analfabetismo, o que contribuiu para o fortalecimento dos grupos populares, no que diz respeito ao enfrentamento da violência e da desigualdade. Nesse sentido, a Educação Popular, proposta durante toda sua vivência, teve/tem por propósito a construção de uma sociedade justa, democrática e com equidade. Essa proposta pedagógica, reafirmada pelos autores Liu, Pini e Góes (2011), considera a realidade da população, disseminada pelos movimentos sociais, valorizando a dialogicidade, a horizontalidade e o conhecimento prévio do sujeito, além de promover a autonomia por meio da ação-reflexão-ação.

\section{Paulo Freire versus o negacionismo na conjuntura atual}

As breves páginas que compõem esse tópico vêm suscitar aspectos da Pedagogia Freiriana e do negacionismo atual que entrelaça os setores da sociedade e da educação como um todo. No Brasil e no mundo, Paulo Freire é lembrado pelo seu legado que inspira uma educação libertadora e transformadora da realidade, justamente por seu pensamento ainda ser contemporâneo e orientar a teoria/prática de docentes, bem como o processo de ensino e aprendizagem dos educandos. No entanto, o contexto político5 que vivenciamos vem passando por constantes alterações negativas, por aqueles que impedem a emancipação da sociedade por meio da educação.

Sobre a questão educacional atual, reforçamos que a situação no ensino superior não fica aquém da educação de base. Nos últimos anos, tem havido severos cortes em bolsas de estudos e em verbas destinadas à ciência e pesquisa nas/das instituições federais, empecendo grande parte dos estudos nacionais. Contudo, a luta dos estudantes e pesquisadores fez o governo recuar em algumas decisões, sendo que estas conquistas da sociedade mostra que a esfera

${ }^{5}$ Período iniciado em 01 de janeiro de 2019 com o capitão reformado, Jair Messias Bolsonaro, 38 ${ }^{\circ}$ presidente do Brasil. 
governamental não tem carta branca para agir como deseja e terá que ouvir as demandas populares. Nesse cenário, pesa o sentimento de incerteza em relação ao futuro educacional do país, pois não sabemos o próximo passo direcionado a educação do país, já que ela não é prioridade pelos governantes no momento.

Diante dessa exposição, ainda é possível ter esperança e continuar sonhando, como o próprio Paulo Freire sempre enfatizou em seus textos. Podemos democratizar o nosso Brasil por meio da educação, livrando-nos dos clientelismos, dos elitismos, dos colonialismos, das corrupções, dos desprezos ao povo, dos apoderamentos das coisas públicas e da figura do salvador da pátria (Mito) (FREIRE, 2006).

Tal cenário ameaçador, e ainda sob efeitos de uma crise sanitária, oriunda do Covid-19, gera desafios significativos à sociedade. Segundo Morel (2021), o negacionismo experienciado, a circulação avassaladora de fake news e os ataques à ciência estimulam o crescimento da extrema-direita e produzem o aumento da necropolítica:

\begin{abstract}
Os negacionismos são diversos e heterogêneos, formando um fenômeno complexo. Ainda assim, eles se articulam. O negacionismo do racismo, por exemplo, está articulado ao negacionismo histórico nos movimentos recentes de negacionismo da escravidão brasileira. $O$ negacionismo da pandemia, por sua vez, está articulado ao negacionismo científico: quem nega a gravidade da Covid-19 parte, muitas vezes, da negação dos discursos científicos. Sem perder de vista as especificidades do negacionismo da pandemia no Brasil, é importante situá-lo também dentro de um movimento mais amplo (MOREL, 2021, s. p.).
\end{abstract}

Nesse sentido, a pós-verdade vem alcançando dimensões no mínimo preocupantes, sobretudo, porque acaba por impactar políticas públicas. Observamos, nesse sentido, o desprezo pela cultura nacional, à censura à divulgação de dados de pesquisas de instituições consagradas, à promoção de aglomerações da população em meio a uma pandemia que ainda não acabou, ao desprezo sobre recomendações de organismos internacionais de saúde e meio ambiente e ao corte de recursos que viabilizam o desenvolvimento científico no país. Diante do avanço do negacionismo científico e da circulação avassaladora de pós-verdades, nos cabe o enfrentamento de difíceis questões (VILELA; SELLES, 2020, p. 4) 
Assim, resta-nos o enfrentamento desses pontos, refletindo sobre tais problematizações com base na extensa obra Freiriana. O que Paulo Freire sempre trouxe como princípio, e lutou por todos à sua volta, é totalmente contrário ao projeto de poder atual movido por interesses próprios, os quais desprezam as instituições propagadoras do pensamento de esquerda, considerado por seus críticos como pensamento "comunista". Freire foi um dos intelectuais brasileiros que conseguiu captar os anseios dos oprimidos e fazer disso uma bandeira de luta, pois tinha a capacidade intelectual de organizar o conjunto dos trabalhadores na década de 1960 para refletir sobre a situação em que viviam. Desse modo, enquanto instrumento de luta política, surgiram os movimentos de cultura popular. Os diversos estados brasileiros, em particular, o estado de nascimento de Paulo Freire, Pernambuco, é a expressão da produção da cultura popular, como transformadora da realidade.

$\mathrm{O}$ atual presidente do Brasil, Jair Messias Bolsonaro, questiona frequentemente o título de Freire - patrono da educação brasileira, concedido ao educador pernambucano pela Lei no12.612/2012, sancionada pela ex-presidenta Dilma Rousseff 6 . O referido tributo ao filósofo foi sugerido pela deputada federal e ex-prefeita de São Paulo (SP), Luiza Erundina7, que teve a consciência de mostrar, não só aos brasileiros, mas ao mundo, a importância desse grande educador. Em sua última entrevista televisionada, a deputada expôs ao público sua opinião sobre o assunto, esclarecendo que a intenção de alguns parlamentares contrários a Freire é justamente "condená-lo a um novo exílio, mesmo após sua morte". A revolta elucidada e as críticas infundadas diante a imagem de Freire transparecem que não são aceitáveis propostas revolucionárias para sociedade, cuja intenção é dar autonomia e capacidade crítica aos sujeitos. Agir, pensar e se libertar é algo não tolerado em uma sociedade autoritária e silenciadora como a que vivenciamos no momento. Sobre esse aspecto, Freire, em seu livro "Educação como prática da Liberdade", expressa claramente essa questão:

\footnotetext{
${ }^{6}$ Período de governo: 2011-2016. Dilma foi afastada antes de cumprir seu mandato, por um processo de impeachment. É economista e política brasileira, filiada ao Partido dos Trabalhadores e a 36a Presidente do Brasil.

7Assistente Sociale política brasileira, filiada aoPartido Socialismo e Liberdade(PSOL) e atualmentedeputada federalpelo estado deSão Paulo. Paulo Freire foi secretário da educação,durante dois anos e cinco meses (1989-1991), sendo sucedido por Mário Sergio Cortella.
} 
Conscientização está evidentemente ligada à utopia, implica em utopia. Quanto mais conscientizados nos tornamos, mais capacitados estamos para sermos anunciadores e denunciadores, graças ao compromisso de transformação que assumimos (FREIRE, 1967, p. 28).

Nessa perspectiva, ponderamos que o objetivo de Freire nunca foi ideologizar ou propor palavras de ordem para as pessoas, como ocorre no momento. Sua intenção era elucidar os caminhos, por meio da educação, para que a classe popular pudesse demonstrar suas insatisfações sociais e entender que uma educação crítica contribui para tomada de decisão e responsabilidade social e política (FREIRE, 2001).

Diante dessa premissa, precisamos entender que o verdadeiro sentido da educação, a partir do olhar de Freire, é fazer com que qualquer indivíduo consiga expressar, criar, recriar, decidir e opinar no mundo, visto que essas ações não podem ser privilégios de uma classe dominante que silencia as demais (FREIRE, 2001). É válido advertirmos, mais uma vez, sobre a incansável recusa política em estimular programas, políticas e ações voltadas para o povo, uma vez que o propósito principal da elite no poder é proibir o “oprimido" de se expressar autenticamente e ser ele mesmo perante seu mundo. Sobre essa alocução, Freire (2007), em seu livro “Ação cultural para a liberdade: e outros escritos”, apresenta: àqueles e àquelas que veem o povo como "naturalmente inferiores e incapazes", e atribuem a estes "inferioridade" e todas as deficiências materiais que existe no cotidiano, [...] sugeriríamos que discutissem um dia com eles sobre o que significa sua existência (FREIRE, 2007, p. 25-26).

Adicionalmente, o autor aponta uma pedagogia utópica, não pela necessidade de nutrir sonhos impossíveis ou defender um perfil abstrato de ser humano, mas sim pelo reconhecimento de uma classe social, com o objetivo de "acarretar ações para construção de um mundo de fraternidade" (FREIRE, 2007, p. 31).

Nesse âmbito, é importante expressar que, do ponto de vista das elites, a questão se apresenta de modo claro. É preciso acomodar as classes populares emergentes, domesticá-las em algum esquema de poder ao gosto das classes dominantes. Portanto, se já não é possível aquela mesma docilidade tradicional, torna-se indispensável manipulá-las de modo a que sirvam aos interesses dominantes e não passem dos limites. De modo geral, a chave para domar o povo é justamente não oferecer ferramentas educacionais para sua libertação, coibindo 
a educação conscientizadora e problematizadora, para que ele não saia da condição de oprimido.

Assim, destacamos que a pedagogia de Freire é de extrema importância para a sociedade, justamente por contribuir para outros olhares sobre o que está acontecendo e sendo oferecido. Diante da atual conjuntura, trazemos o que se presencia no momento: oferecer menos para os que sempre se nutriram de pouco. Tais críticas são direcionadas para as ações assistencialistas de governo para/com o povo. Sobre esse pressuposto, Freire (1992) adverte:

Em primeiro lugar, contradiziam a vocação natural da pessoa - a de ser sujeito e não objeto, e o assistencialismo faz de quem recebe a assistência um objeto passivo, sem possibilidade de participar do processo de sua própria recuperação. Em segundo lugar, contradiziam o processo de "democratização fundamental" em que estávamos situados (FREIRE, 1992, p. 58).

Em suma, o grande perigo do assistencialismo ${ }^{8}$, diante da concepção Freiriana, está na violência do seu antidiálogo, ao oferecer a homens e mulheres apenas o mínimo, impedindo o pleno desenvolvimento ou a "abertura” de sua consciência e de sermos mais, na visão de Freire. Sem a democracia autêntica, "sem esta consciência cada vez mais crítica, não será possível ao homem brasileiro integrar-se à sua sociedade em transição, intensamente cambiante e contraditória" (FREIRE, 1992, p. 33).

Para o autor, não se pode aceitar, impassível, a política assistencialista que se oferece, pois esta anestesia a consciência oprimida e prorroga a necessária mudança da sociedade. Em relação à política, Freire ainda alerta que a educação não significa proibir os oprimidos a votarem em candidatos reacionários, "mas sim adverti-los do erro que cometem, da contradição em que se emaranham. Para ele votar no político reacionário é ajudar a preservação do "status quo” (FREIRE, 2001, p. 42).

Conscientização e inédito viável constituem, também, outras categorias trabalhadas por Freire. Ele salienta, em seus escritos, que os referidos termos estão relacionados ao mundo, implicando em uma utopia. Quanto mais

\footnotetext{
${ }^{8} \mathrm{O}$ assistencialismo é uma forma de ajuda paliativa aos necessitados, ou seja, uma prática de dominação que de certo modo produz a manipulação do sujeito/situação. As Políticas Públicas são a totalidade de ações, metas e planos que os governos (nacionais, estaduais ou municipais) traçam para a sociedade sem a sua participação.
} 
consciente/conscientizado, mais é possível ser capaz de anunciar/denunciar o mundo, assumindo um compromisso de transformação social e superação. Assim, se o sujeito se afasta da realidade, ele pode entender o mundo de forma mistificada ou distorcida (SOUZA; MELLO, 2020).

Daí a ênfase dada ao papel da conscientização e do diálogo por meio da educação. Desse modo, a intenção de Freire nunca foi ditar ordens a serem seguidas, o que significaria uma impactante contradição a todo seu legado (FREIRE, 2006). Pelo contrário, o que lhe sempre interessou foi desafiar seus leitores em torno de certos pontos ou aspectos, insistindo que há sempre algo diferente a se fazer na nossa cotidianidade educativa, quer dela participemos como aprendizes ou ensinantes.

Quanto ao cotidiano educativo, destacamos o papel do docente, que necessita estar sempre atento e conectado à leitura de mundo dos seus educandos. Para Freire, o aprendizado do docente ao ensinar não se dá necessariamente através da retificação que $o$ aprendiz lhe faça de erros cometidos (FREIRE, 2000). O aprendizado do docente ao ensinar se verifica à medida em que o(a) professor(a), humilde, aberto(a), se coloca permanentemente disponível a repensar sua prática, revendo suas posições e avaliando diferentes caminhos e possibilidades.

Além disso, nós, educadores, devemos respeitar os diferentes níveis de compreensão que os educandos possuem, não importando quem sejam ou de qual realidade eles advêm. Impor aos (às) alunos (as) uma única compreensão sobre o mundo e da sua própria educação é aceitar soluções autoritárias que negam a solidariedade entre o ato de educar ou de ser educado (FREIRE, 1996).

Há, portanto, uma visão equivocada dos atos de ensinar e de aprender e do que vem a ser um bom aluno. Freire (1996) elucida certos lapsos no cotidiano escolar: o bom aluno não é "o inquieto, o indócil, o que revela sua dúvida, o que quer conhecer a razão dos fatos, o que rompe os modelos prefixados, o que denuncia a burocracia e o que recusa ser objeto" (FREIRE, 1996, p. 43). O bom aluno, diante a grande maioria, será justamente o que repete e o que renuncia para pensar criticamente, se posicionando diante de modelos impostos, ou seja, o aluno(a) que não dialoga e nem discute sobre o que lhe é apresentado.

Tal alocução do "bom aluno" se encaixa perfeitamente na concepção bancária, conforme descrito por Freire (1996): 
[...] "bancário", que deforma a necessária criatividade do educando e do educador, o educando a ele sujeitado pode, não por causa do conteúdo cujo "conhecimento" lhe foi transferido, mas por causa do processo mesmo de aprender, dar, como se diz na linguagem popular, à volta por cima e superar o autoritarismo e o erro epistemológico do "bancarismo" (FREIRE, 1996, p. 14).

Nesse sentido, por mais que o educando esteja submetido à educação bancária, este necessita manter vivo o gosto da rebeldia e da curiosidade no aprender, de forma a estimular sua capacidade de arriscar-se e de aventurar-se, contra a capacidade apassivadora e monótona do "bancarismo". Desse modo, é a força criadora do aprender de que fazem parte a comparação, a repetição, a constatação, a rebeldia, a curiosidade que supera os efeitos negativos do falso ensinar na prática educativa (FREIRE, 1996).

Em seus escritos, Freire sempre estimulou a importância dos saberes socialmente construídos na comunidade em que o educando vive, no sentido de dialogar a razão de ser de alguns desses saberes em relação ao ensino de conteúdos, com a finalidade de problematizar o que está sendo aprendido. Nessa perspectiva, o docente deve aproveitar as experiências dos alunos, para contextualizar questões da sua comunidade como: a poluição dos rios e dos córregos, o bem-estar da sua comunidade, os riscos à saúde, a degradação do meio ambiente, entre várias outras situações (FREIRE, 1996).

Sob esse viés, ressaltamos que o ato de ensinar exige risco, aceitação do novo e rejeição a qualquer forma de discriminação. Na prática docente, a partir de ideais Freirianos, o ensino exige bom senso e vigilância das ações, cuja importância é enorme mediante avaliação de que, a todo instante, devemos perfazer a prática. Algo totalmente contrário ao negacionismo experienciado e propagado pelo governo, que busca atacar a imagem Freire, defensor de uma educação libertária, de forma a gerar dúvidas sobre seu legado, com o intuito de alienar a população em prol dos seus interesses político-ideológicos.

De tal maneira, o ato de ensinar deve ser vinculado ao respeito à autonomia, à dignidade e à identidade do educando, procurando contextualizar sempre a bagagem de conhecimento oferecida. Assim, de nada serve, "a não ser para irritar o educando e desmoralizar o discurso hipócrita do educador, falar em 
democracia e liberdade, mas impor ao educando a vontade arrogante do mestre" (FREIRE, 1996, p. 32).

Consideramos, assim, que a competência técnico-científica e o rigor não são incompatíveis com a amorosidade necessária às relações educativas. É necessário construir um ambiente favorável à produção do conhecimento, a fim de desvelar o medo do professor e do mito criado em torno da sua figura.

Nesse sentido, ensinar exige do indivíduo humildade, tolerância e luta em defesa dos direitos dos educadores. Se há algo que os educandos brasileiros precisam saber, desde a mais tenra idade, é que a luta em favor do respeito aos educadores e à educação inclui salários menos dignos, sendo este um dever irrecusável e não só um direito. Portanto, a luta dos professores em defesa de seus direitos e de sua dignidade deve ser entendida como um momento importante de sua prática docente, enquanto prática ética (FREIRE, 1996).

Freire confirma que o combate em favor da dignidade da prática docente é tão parte dela mesma quanto dela faz parte, abrangendo "o respeito que o professor deve ter à identidade do educando, à sua pessoa, a seu direito de ser" (FREIRE, 1967, p. 34 -35). Por isso, um dos piores males que o poder público vem fazendo à classe docente, no Brasil, é o descaso pela educação pública, que culmina na indiferença, acarretando, diante desse cruzamento dos braços, uma atitude acomodada que o povo não pode aceitar.

A partir das pontuações supracitadas, advertimos para o momento de desvalorização do trabalho do professor em todos os níveis, evidenciando que a pedagogia de Freirianos apresenta elementos constitutivos para a compreensão da prática docente enquanto dimensão social da formação humana. Freire (1996) ressalta a necessidade de assumirmos uma postura vigilante contra todas as práticas de desumanização. Para que isso ocorra, é de suma importância a formação permanente dos professores, para que estes tenham a oportunidade de pensar e de refletir sobre a própria prática. Segundo Freire, é "pensando criticamente a prática de/ou ontem que se pode melhorar a próxima ação" (FREIRE, 1996, p. 26).

Acerca desse assunto, durante a formação contínua/permanente, observamos que o conteúdo teórico, necessário à reflexão crítica, tem de ser concreto, pois "quanto mais estou sendo e percebo a/ou razões de ser porque estou sendo assim, mas me torno capaz de mudar, de promover-me, no caso, do 
estado de curiosidade ingênua para o de curiosidade epistemológica" (FREIRE, 1996, p. 51). Assim, tanto o docente quanto o educando, e a sociedade em si, necessitam querer trilhar caminhos que os levem à compreensão de mecanismos políticos, sociais ou culturais, em prol da mobilização e conscientização das massas, para que, dessa forma, tenham clareza e saibam opinar sobre as questões ao seu redor.

Um dos principais enfoques da Pedagogia Freiriana, que se torna tão contemporâneo, é elucidar a educação como principal ferramenta para liberdade e transformação de uma sociedade. Nesse cenário, a conscientização no ato de educar e a política atrelada à educação revelam ao educando a verdadeira realidade em que se vive.

$\mathrm{O}$ ato de agir e de refletir perante a sociedade intercruza o passado e o presente, no que diz respeito à reflexão e à prática pedagógica do âmbito educacional e da sociedade atual em si. Nesse aspecto, Freire sempre esteve engajado em contribuir para possíveis mudanças sociais, econômicas, culturais e políticas através da educação, visto que suas ações sempre estiveram voltadas ao povo e não às elites, estando ainda tão presentes mesmo após sua morte.

\section{CONSIDERAÇÕES FINAIS}

Neste artigo, debatemos experiências sobre Educação Popular, perpassando discussões em torno da pedagogia libertadora de Paulo Freire, como caminho alternativo para superação e enfrentamento de situações desafiadoras, diante do atual negacionismo vivido em nosso país.

Estamos em um cenário político que duvida e subjuga a educação e a ciência, assim como todos(as) aqueles(as) que venham a ser contrários(as) às suas propostas ou que ameacem essa liderança. Isso posto, visamos construir nossa argumentação com base nas obras de Paulo Freire (e de estudiosos do seu legado), o que muito pode contribuir para ressignificar os ideais do contexto atual, uma vez que a Pedagogia Freiriana valoriza a educação e outros setores essenciais para o bem-estar dos cidadãos brasileiros.

Nós, docentes e pesquisadores, carregamos como proposta a educação popular e humanizadora, baseada na solidariedade, a fim de extrair o melhor do "outro", dando-lhe a oportunidade de refletir sobre suas próprias ações, 
auxiliando-o para sua própria humanização. Assim, aproveitamos para ressaltar que urge a necessidade de novas pesquisas educacionais que concretizem o legado Freiriano, de forma a combater e atravessar a obscuridade vivenciada.

Nesse horizonte, na perspectiva da Educação Popular e da Pedagogia Freiriana, é possível cumprir a tarefa de não se omitir diante a vida, o que vale para nós cidadãos e para as autoridades, sobretudo no ato de educar, de se responsabilizar pelo bem-estar e pela boa convivência, em prol de uma luta coletiva que propicie transformações sociais (fator fundamental na reinvenção do mundo, sobretudo após uma crise sanitária).

Reforçamos que a Educação Popular é uma concepção que permite à escola pública e às instituições de ensino superior uma revisão/reflexão de seu dever. Necessita abranger uma compreensão ético-política que necessariamente nos convida a assumir nossa responsabilidade para/com o "outro", diante da necessidade de pensarmos o nosso tempo, planejarmos o futuro e construirmos o inédito viável, conforme argumenta Paulo Freire.

\section{REFERÊNCIAS}

FREIRE, Ana Maria Araújo. Notas explicativas. In: FREIRE, Paulo (Org). Pedagogia da esperança: um reencontro com a pedagogia do oprimido. 21 ed. São Paulo: Paz e Terra, 2014. p. 273-333.

FREIRE, Ana Maria Araújo. Paulo Freire: uma história de vida. Indaiatuba, SP: Villa das letras, 2006.

FREIRE, Paulo. A educação na cidade. São Paulo: Cortez, 2000.

FREIRE, Paulo. Ação cultural para a liberdade: e outros escritos. 12 ed. São Paulo: Paz e Terra, 2007.

FREIRE, Paulo. Conscientização: Teoria e Prática da Libertação - Uma introdução ao pensamento de Paulo Freire. São Paulo: Moraes, 1980.

FREIRE, Paulo. Educação como prática da liberdade. Rio de Janeiro: Paz e Terra, 1967.

FREIRE, Paulo. Pedagogia da autonomia: Saberes necessários à prática educativa. 25 ed. São Paulo: Paz e Terra, 1996.

FREIRE, Paulo. Pedagogia da Esperança: reencontro com a Pedagogia do Oprimido. Rio de Janeiro: Paz e Terra, 1992. 
FREIRE, Paulo. Pedagogia da Indignação: cartas pedagógicas e outros escritos.São Paulo: Ed. UNESP, 2000.

FREIRE, Paulo. Pedagogia do oprimido. 8 ed. Rio de Janeiro: Paz e Terra, 1980.

FREIRE, Paulo. Política e educação. 8 ed. São Paulo: Villa das Letras, 2007.

FREIRE, Paulo. Política e educação: ensaios. 5 ed. São Paulo, Cortez, 2001.

FREIRE, Paulo; MACEDO, Donaldo. Alfabetização: leitura do mundo, leitura da palavra. Tradução de: Lólio Lourenço de Oliveira. 6 ed.Rio de Janeiro: Paz e Terra, 2013.

GOHN, Maria da Glória.Educação Popular na América Latina no Novo Milênio: Impactos do Novo Paradigma.Educação Temática Digital, Campinas: v.4, n.1, 2002.

LIU, Emiliano Palmada; PINI, Francisca Rodrigues de Oliveira; GÓES, Washington. Educação Popular. São Paulo: Instituto Paulo Freire, Caderno MOVA-Brasil, v. 3, 2011.

MENEZES, EbenezerTakuno de. Verbete Mova.Dicionário Interativo da Educação Brasileira - EducaBrasil. São Paulo: Midiamix Editora, 2001. Disponível em <https://www.educabrasil.com.br/mova/>. Acesso em o1 jul 2021.

MOREL, Ana Paula Massadar. Negacionismo da Covid-19 e educação popular em saúde: para além da necropolítica. Ensaio- Trab. educ. saúde 19, 2021.

PINI, Francisca Rodrigues de Oliveira. Educação popular em direitos humanos no processo de alfabetização de jovens, adultos e idosos: uma experiência do projeto Mova-Brasil. Educação em revista (Online), v. 35, p. 45, 2019.

ROMAO, J. E. ; ROMAO, N. P. O centenário Paulo Freire - o legado de uma obracinquentenária contra os Gabinetes do ódio?. Revista Unifreire, v. 8, p. 109-124, 2020.

ROQUE, T. O negacionismo no poder, Revista Piauí, 161, Fev/2020. Disponível em: <https://piaui.folha.uol.com.br/materia/o-negacionismo-nopoder/>. Acesso em: 31 out. 2021.

SOUZA, V. E. B.; MELLO, R. M. A. V. Pensar, agir e se libertar: concepções da pedagogia freiriana para a educação. Revista Olhar de Professor, v. 23, p. 1$13,2020$.

VILELA, M. L. ; SELLES, S. E. É possível uma Educação em Ciências crítica em tempos de negacionismo científico?. Caderno Brasileiro de Ensino de Física, v. 37, p. 1722-1747, 2020. 


\section{Sobre os autores}

Valdirene Eliane Bailon de Souza. Graduada em Pedagogia pela Universidade Federal de Viçosa (UFV). Mestra em Educação e doutoranda pelo Programa de Economia Doméstica na linha de pesquisa Famílias, Políticas Públicas e Desenvolvimento Humano e Social, pela UFV. É integrante do grupo de pesquisa "Políticas Públicas e a formação de profissionais da Educação" (GEPPFOR).E-mail: $\quad$ vbailondesouza@gmail.com $\quad$ ORCID: https://orcid.org/o0oo-0002-9855-4823

Nádia Marota Minó. Graduada em Pedagogia. Mestra e Doutora em Economia Doméstica pela Universidade Federal de Viçosa (UFV). Especialista em Gestão Escolar e Coordenação Pedagógica e professora da Educação Infantil na Rede Municipal de Ensino em Viçosa/MG.E-mail: nadiamino@gmail.com ORCID: https://orcid.org/o000-0002-2932-9710

Rita Márcia Andrade Vaz de Mello. Graduada em Pedagogia e Mestra em Extensão Rural pela Universidade Federal de Viçosa (UFV). Doutora em Educação pela Universidade Federal de Minas Gerais (UFMG). Pós-Doutora pela Université Paris Descartes (Sorbonne). Professora e pesquisadora do Programa de Pós-graduação em Economia Doméstica da UFV. Coordenadora do grupo de pesquisa Políticas Públicas e a formação de profissionais da Educação (GEPPFOR). $\quad$ E-mail: $\quad$ ritamarciamello@gmail.com $\quad$ ORCID https://orcid.org/o000-0002-7473-9559

\section{Tramitação:}

Recebido em:21/o7/2021

Aprovado em:29/10/2021 